\title{
An Overview of Pesticide Residue in Agricultural Soils
}

\author{
ALAEKWE, I.O ${ }^{1 *}$ ABBA, $\mathrm{O}^{2}$ \\ 1.Department of Chemistry, Federal University Gusau, Zamfara State Nigeria \\ 2.Department of Microbiology, Federal University Gusau, Zamfara State Nigeria \\ *Email: iykemome.io@gmail.com_Email: oluchijoan@gmail.com
}

\begin{abstract}
Agriculture has become the main stay of most growing economies. This has given rise to changes in traditional farming methods. One of such change is in the use of pesticides. Pesticides are substances used inside or outside to prevent, control, repel, or kill insects, plants, fungi, and other pests. Application of pesticides for agricultural production has risen to an alarming level particularly in developing countries often living behind residues which persists in the ecosystem. The mechanism of action of pesticide is aimed at killing pests or rendering them ineffective. However, they can also act upon unintended organisms, such as humans. A number of health issues have been linked with pesticides in the environment. It is against this background that the recent paper attempts to discuss pesticide residue in the soil with a view to providing guidance to pesticide users and policy makers. The paper focuses on classification of pesticides, fate of pesticides in the soil, degradation of pesticides, factors affecting levels of pesticide residue in the soil, health hazards associated with pesticides, present situation of pesticide residue in agricultural soil and way forward.
\end{abstract}

Keywords: Pesticides, Agricultural soil, Organochlorides, DDT, Health

DOI: $10.7176 / \mathrm{JBAH} / 12-4-02$

Publication date: February $28^{\text {th }} 2022$

\section{Introduction}

In developing countries, the level of pesticides application for agricultural production is severe due to efforts to terminate insects' borne-diseases, protect farms and produce sufficient food (Schumann, 2004; Giri, et al., 2012). About 900 chemical pesticides are still used worldwide with various food products and the treatment of crops and soils (Thurman \& Zweigenbaun, 2008 ; Giri et al 2012). In Nigeria, close to 15000 metric tons of pesticides comprising of about 135 pesticides chemicals are imported into the country annually (Erhunmwunse et al 2012). Health and environmental issues have been associated with many of these pesticides (Nicolopoulou-Stamati et al 2016).

In 2007, an expected $498951607 \mathrm{~kg}$ of pesticides were utilized in the U.S., and $2358680324 \mathrm{~kg}$ were utilized internationally. This estimation incorporates both engineered pesticides and different synthetic substances utilized as pesticides, including sulfur and petroleum oil. Buildups from these pesticides regularly stay on or in produce, accordingly making a wellspring of human openness when these things are ingested (EPA, 2006). Pesticides work through systems of activity expected either to kill pests or render them unproductive (Casida, 2009). Accordingly, they can also act upon unintended organisms, such as humans. Kids specifically might be vulnerable to unfavourable neurological, formative and different impacts from pesticide exposures (Weiss et al 2004; NRC,1993).

Roughly, 2 million tons of pesticides are used yearly around the world, with China as the major contributing nation, trailed by the United States America and Argentina, which is expanding very quickly. It was projected that by the year 2020, the worldwide pesticide usage may see an increment up to 3.5 million tons (Sharma et al 2019). The fundamental qualities of organochlorine pesticides are high persistence, low polarity, low fluid dissolvability and high lipid solvency. Organochlorine pesticides can enter the environment after pesticide applications, polluted wastes disposed of into landfills, and releases from manufacturing units (Javaraj et al, 2016).

The use of dichlorodiphenyltrichloroethane (DDT) has been banned in many countries. However, it is illegally used in most of the developing countries. This applies also to endosulphan, an insecticide which is highly hazardous and has moderate persistence with a half-life of fifty days (Quijano, 2002). Recent information and World Health Organization (WHO) statistics since 2008 show that, 346,000 people pass on worldwide because of inadvertent pesticide poisonings, two-thirds of this number occurring in developing countries (Prüss-Ustün et al 2011 ; WHO, 2008).

\section{Classification of pesticides}

Different terms such as chemical classes (functional group), modes of action, and toxicity have been used to classify pesticides (Tudi et al 2021). Depending on their chemical compositions, pesticides are broadly classified as either organic or inorganic pesticides. Organic pesticides are water insoluble, but readily soluble in fatty acids. Most of the recent pesticides are organic chemicals, which often contain oxygen, phosphorus, or sulphur in their molecules. They are further classified as organochlorides, organophosphates or carbamates etc (Perera \& Dulmini, 
2020). Inorganic pesticides are characterized by crystalline, salt-like appearance; these are environmentally stable and usually soluble in water. e.g. sulphur, aluminium phosphide, lime, arsenic, copper and mercury salt which are generally toxic and can persist in the environment (Perera \& Dulmini, 2020).

Based on toxicity, pesticides have been classified into two; acute and chronic. Acute toxic pesticides refer to pesticides that can cause injury to a person or animal from a single exposure, generally of short duration. Acute toxicity is measured as the amount or concentration of a toxicant - that is required to kill 50 percent of the animals in a test population. This measure is usually expressed as lethal dose $50\left(\mathrm{LD}_{50}\right)$ or lethal concentration $50\left(\mathrm{LC}_{50}\right)$ (Winard, 2016; Akashe et al 2018). Any harmful effects that occur from small doses repeated over a period of time are termed chronic effects. Thus chronic toxic pesticide refers to pesticides that can cause injury over a long time by continuous exposure. It is determined by subjecting test animals to long-term exposure to the active ingredient (Akashe et al, 2018).

Pesticides are classified on the basis of their mode of action depending on the type of pesticides as; Contact, Stomach acting, systemic, fumigants and non - selective (Marcus, 2021). (a) Contact: This class kills only insects they are sprayed or dusted onto. (b) Stomach acting: This class of pesticides kills only insects that eat plant parts sprayed with insecticide. (c) Systemic: This type of insecticide is transported within the plant and kills insects when they suck sap or eat parts of the plant. (d) Fumigant: this kills insects that inhale toxic vapors of the chemical. (e) Non - selective pesticides kills all pest upon which it comes in contact with.

\section{Pesticides in the soil and their effects}

The soil is not only important for food production; it performs other fundamental environmental functions, including acting as a carbon-sink, breaking down atmospheric pollutants, and maintaining the natural cycling and recycling of nutrients. Pesticides used in agriculture are artificial in origin and get absorbed in the soil through surface overflow from treated plants ${ }^{10}$. The application of pesticides may threaten aboriginal microorganisms of soil and affect the soil ecosystem, thus entering in food chain and affecting human health (Hussain et al 2009). Pesticides interact with soil microbes and their activities thereby changing the biochemical and physiological behaviour of soil microbes (Singh \& Walker, 2006). Agricultural use of pesticides can have considerable positive and negative impacts on the soil including reduction on natural soil processes. Some pesticides can persist in the soil, where they may affect organisms that play a part in soil processes. Pesticides also have negative impact on soil microbial biomass and soil respiration (Zhou et al, 2006).

\subsection{Effects on wildlife}

Department for Environment Food and Rural Affairs, (DEFRA) reported that increased use of pesticides is one aspect of a general intensification of agriculture over the past fifty years that has been associated with a marked decline in farmland wildlife. In normal use of pesticides, it is rare to observe poisoning of birds and larger animals. However, drift and over-spraying can affect hedges, grass banks, field margins, and other wildlife habitats that may lie alongside the sprayed area. Farmland birds in particular have declined significantly during the past few decades. Insects are an important part of the diet of the chicks of birds such as partridges, skylarks, sparrows and most of the finches; as a result their availability during the breeding season is likely to be significant to the ability of these birds to maintain their populations (DEFRA, 2011).

\subsection{Fate of pesticides in the environment}

A couple of activities take place when pesticides are applied. Some of the pesticides are eroded by wind action and are carried to place they are not intended for, others get deposited on the soil were sorption takes place. From the soil, they may be leached towards the groundwater system and some may go into the surface waters during runoffs. Others may be degraded chemically or acted upon by microbial agents and of course some may find there way into humans through inhalation or ingestion. 


\section{Chemical fate processes}

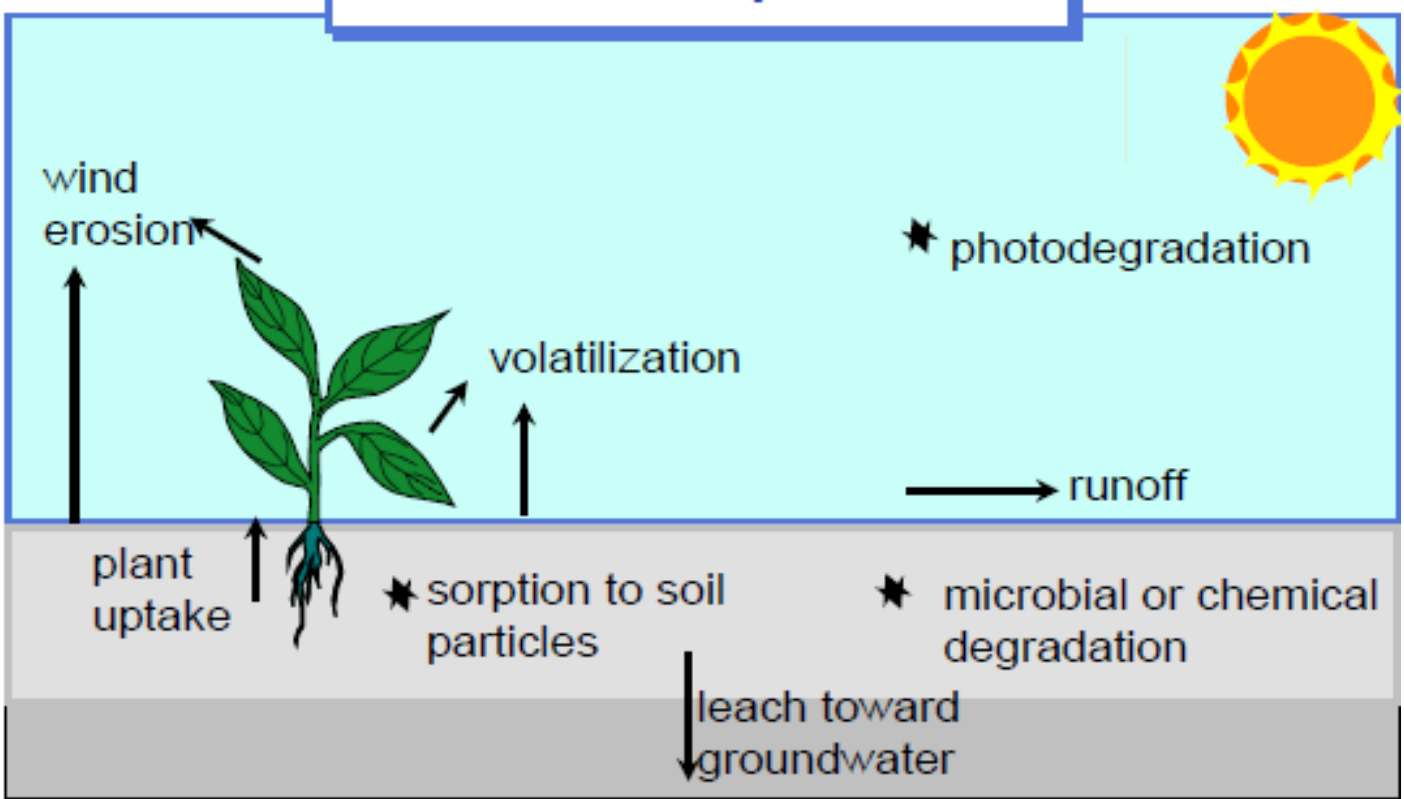

Fig 1: chemical fate of pesticides. Source (Field, 2013)

\subsection{Mechanism of pesticides degradation.}

Pesticides in the soil could be degraded by different ways; the methods included chemical degradation (abiotic), microbial degradation and photo degradation. Although biodegradation of pesticide is considered the most important degradation pathway (Nowak et al 2011), remnants of multiple pesticides persisting at low but detectable and environmentally significant concentrations in soils are still observed (Wirsching et al 2020). As a result, soils shift from serving as sinks of pesticides to secondary sources of pesticides (Miglioranza et al 2002).

Many chemical molecules if directly hit by the energy of the Uv-radiation can be broken. Pesticides that do not absorb Uv-radiations directly are transformed by oxidizers formed by sunlight.

Products of degradation are often more soluble in water, which gives rise to mobility in soil and runoff or leaching to groundwater. The mechanism and rate of pesticide degradation is dependent upon a number of factors (fig 2)

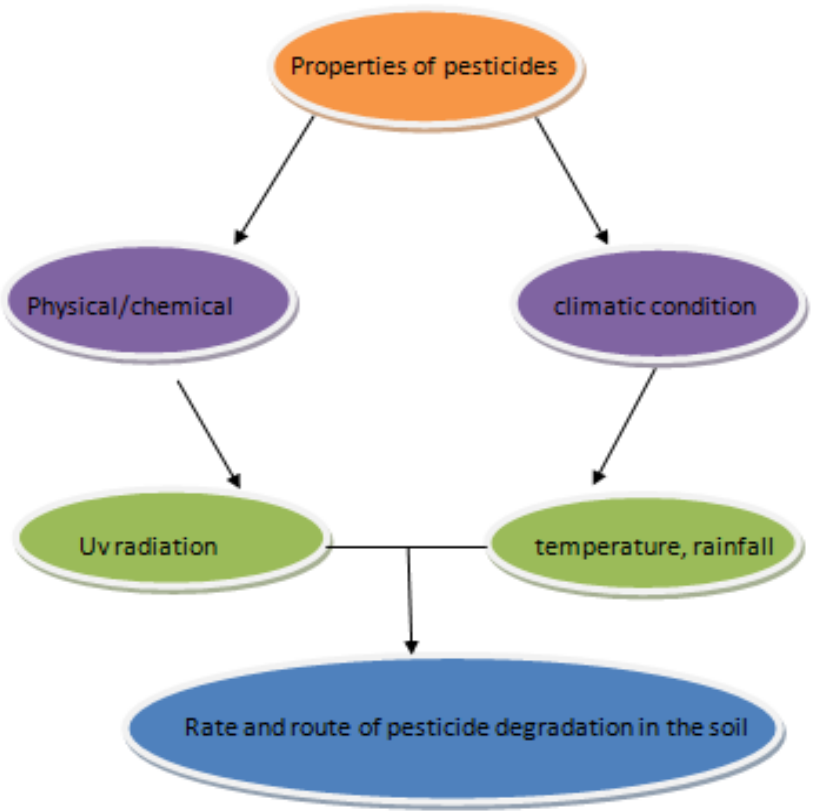

Fig 2: Factors of pesticide degradation 


\section{Health effects of pesticides residues}

Residues of pesticides can be found everywhere and many of the pesticides have been associated with health issues. Pesticides may be metabolized, excreted, stored, or accumulate in body fat within human or animal body (Nicolopoulou-Stamati et al 2016). Two broad categories of health effects are caused by pesticides, short-term (or acute) effects and long-term (or chronic) effects. Pesticide residues absorbed by inhalation, ingestion, and dermal contact can lead to acute and chronic toxicity. Such kinds of the toxicity depend on types of pesticides, point of entry, dose, metabolism, accumulation among others. Acute toxicity is due to short-term exposure and happens within a relatively short period of time, whereas chronic toxicity is due to repeated or long-term exposure and happens over a longer period. Mainly it interrupts the metabolic and systemic functions of the human body. The chemical compound of pesticide disrupts the neurological function and is injurious to the immune and endocrine systems as well (Roberts et al 2012). Ojo, 2016 also reports that chronic effects of pesticide poisoning are mainly neurological, reproductive, developmental, carcinogenic, and immunological while acute toxicity is associated with commonly used organophosphorus and carbamate compounds which gave rise to neurobehavioral effects, gastro-intestinal effects, and respiratory effects.

Chronic health effects include cancer, brain and nervous system damage; birth defects; infertility and other reproductive problems; and damage to the liver, kidneys, lungs and other body organs. Acute health effects from pesticide exposure includes irritation of the nose, throat, and skin, causing burning, stinging and itching as well as rashes and blisters. Nausea, dizziness and diarrhea are also common (Gyawali, 2018).

\section{Present situation of pesticide residue in agricultural soils}

Silva et al 2019 reported that soil contamination by pesticide residues has become an issue of increasing concern due to some pesticides' high soil persistence and toxicity to non-target species. In the study, the distribution of 76 pesticide residues was evaluated in 317 agricultural topsoil samples from across the European Union. Over 80\% of the tested soils contained pesticide residues $(25 \%$ of samples had 1 residue, $58 \%$ of samples had mixtures of two or more residues), in a total of 166 different pesticide combinations. Maximum individual pesticide content assessed in a soil sample was $2.05 \mathrm{mg} \mathrm{kg}^{-1}$ while maximum total pesticide content was $2.87 \mathrm{mg} \mathrm{kg}^{-1}$. This study reveals that the presence of mixtures of pesticide residues in soils is the rule rather than the exception.

Reido, et al 2021 screened 100 fields under organic and conventional management with an analytical method containing 46 pesticides ( 16 herbicides, 8 herbicide transformation products, 17 fungicides, seven insecticides). Pesticides were found in all sites, including 40 organic fields with the number of pesticide residues and the concentration found to be two and nine times higher respectively in conventional compared to organic fields. Pesticide number and concentrations significantly decreased with the duration of organic management. The study demonstrates that pesticides are a hidden reality in agricultural soils, and the results suggest that they have harmful effects on beneficial soil life.

Sharma et al 2019, reported that by the year 2020, the global pesticide usage has been estimated to increase up to 3.5 million tonnes. In their research, they posited that although pesticides are beneficial from the crop production point of view, extensive use of pesticides can possess serious consequences because of their biomagnification and persistent nature.

Bahndari et al 2020, reports that soil contamination by pesticide residues is a primary concern because of the high soil persistence of pesticides and their toxicity to humans. The researchers investigated pesticide concentration and distribution at 3 soil depths in 147 soil samples from agricultural land and assessed potential health risks due to non-dietary human exposure to pesticides in Nepal. About sixty percent of the soil samples had pesticides ( $25 \%$ of the soil samples had single residue, $35 \%$ of the soil samples had mixtures of 2 or more residues) in 39 different pesticide combinations. Pesticide residues were found more frequently in topsoil. Overall, the concentration of pesticides ranged from $1.0 \mathrm{mg} \mathrm{kg} 1$ to $251 \mathrm{mg} \mathrm{kg} 1$, with a mean of $16 \mathrm{mg} \mathrm{kg} \_$. The concentration of the primary group, organophosphates (OPs), ranged from $1.23 \mathrm{mg} \mathrm{kg} 1$ to $239 \mathrm{mg} \mathrm{kg} \_1$, with a mean of $23 \mathrm{mg} \mathrm{kg}$ 1. Chlorpyrifos and 3,5,6-trichloro-2-pyridinol (TCP) were the predominant contaminants in soils. The ionic ratio of DDT and its degradation products suggested a continuing use of DDT in the area. Human health risk assessment of the observed pesticides in soil suggested negligible cancer risks and negligible noncancer risks based on ingestion as the primary route of exposure. The predicted environmental concentrations (PECs) of pesticides were higher than the values found in the guidance for soil contamination used internationally. Low concentrations of residues in the soils from agricultural farms practicing integrated pest management (IPM) suggest that this farming system could reduce soil pollution in Nepal.

Ukalska-Jaruga et al, 2020 assessed pesticides residue content in Polish agricultural soils. The study was aimed at evaluating contemporary concentrations of organochlorine (OCPs) and non-chlorinated pesticides (NCPs) in arable soils of Poland as an example of Central and Eastern European countries. The obtained results indicated that residues of the analyzed pesticides originate from historical agricultural depositions which do not potentially pose a direct threat to human and animal health. 


\section{Conclusion and suggestion}

Pesticides are ever-present in the environment and are considered a significant environmental threat to health particularly those in rural areas. There is need for continuous awareness creation with respect to these chemicals. This is because a large variety of chemicals and mixtures are used as pesticides many of which are used at the same time in the same agricultural regions. Pesticides are known to cause significant changes in the functioning of soil microflora and also affect the soil microbial biomass. Pesticides can impact larger fauna that help maintain the structure and fertility of the soil. Maintaining the right balance between bacterial and fungal populations in the soil is important for capturing more carbon. Residues of chlorinated pesticides are present in the air, soil, and water, as well as in most humans. Organophosphate and carbamate pesticides the compounds comprising the bulk of current pesticide use are carried around the globe on air currents. Pesticides are primarily neurotoxins, causing both acute symptoms as well as chronic effects from repeated low-dose exposures. These compounds adversely affect the immune system; causing cell mediated immune deficiency, allergy, and autoimmunity. Literatures have shown that pesticides are useful in a number of ways. However, health issues associated with its use is grave and as such care should be taken in its deployment. Environmental protection agencies of countries across nations should intensify effort aimed at enlightening rural farmers on the indiscriminate use of agrochemicals. Environmental risk assessment procedures should be adapted accordingly to minimize related risks to soil life.

\section{Conflict of interest}

There are no conflicts of interests

\section{Acknowledgement}

The authors are grateful to the research unit of Federal University Gusau, Zamfara State and TETFUND for providing the fund. "TETF/DR\&S/CE/UNIV/GUSAU/IBR/2020/VOL.1"

\section{References}

1. Akashe, M. M., Pawade, U. V., \& Nikam, A. V. (2018). Classification of pesticides: a review. International Journal of Research in Ayurveda and Pharmacy, 9(4), 144-150.

2. Bhandari, G., Atreya, K., Scheepers, P. T., \& Geissen, V. (2020). Concentration and distribution of pesticide residues in soil: Non-dietary human health risk assessment. Chemosphere, 253, 126594.

3. Casida, J.E., (2009). Pesttoxicology: The Primary Mechanisms of Pesticide Action. Chem Res Toxicol, 22(4):609- 19

4. Department for Environment Food and rural Affairs (2011) "Pesticide Use - The EnvironmentalIssue.http://adlib.everysite.co.uk/adlib/defra/content.aspx?id=000IL3890W.17UT2E0Y3FU3 6P. Accessed 17/12/2021. 4:25am.

5. Erhunmwunse, N. O., Dirisu, A., \& Olomukoro, J. O. (2012). Implications of pesticide usage in Nigeria. Tropical Freshwater Biology, 21(1), 15-25.

6. Field, J. A. (2013). Environmental Fate of Pesticides. Oregon State University Department of Environmental and Molecular Toxicology, Non-crop Vegetation Management Course.

7. Giri, N., Mentler, A., Sieghardt, M., Blum, W. E. H., \& Lesueur, C. (2012). A preliminary study of the content and distribution of pesticide residues in soil samples from the Kathmandu valley, Nepal. Spanish journal of soil science, 2(3), 20-31

8. Gyawali, K. (2018). Pesticide uses and its effects on public health and environment. Journal of Health Promotion, 6, 28-36.

9. Hussain S, Siddique T, Saleem M, Arshad M, Khalid A (2009) Impact of pesticides on soil microbial diversity, enzymes, and biochemical reactions. Adv Agron 102:159-200

10. Jayaraj, R., Megha, P., \& Sreedev, P. (2016). Organochlorine pesticides, their toxic effects on living organisms and their fate in the environment. Interdisciplinary toxicology, 9(3-4), 90.

11. Marcus, L.R "Pesticide classification" http://health.gov.vc/health/images/PDF/SAICM/ accessed 15/12/2021 3:30am

12. Miglioranza, K. S., Sagrario, M. D. L. A. G., de Moreno, J. E. A., Moreno, V. J., Escalante, A. H., \& Osterrieth, M. L. (2002). Agricultural soil as a potential source of input of organochlorine pesticides into a nearby pond. Environmental Science and Pollution Research, 9(4), 250-256.

13. National Research Council. (1993). Committee on Pesticides in the Diets of Infants and Children Washinton D.C.

14. Nicolopoulou-Stamati, P., Maipas, S., Kotampasi, C., Stamatis, P., \& Hens, L. (2016). Chemical pesticides and human health: the urgent need for a new concept in agriculture. Frontiers in public health, 4, 148.

15. Nowak, K. M., Miltner, A., Gehre, M., Schäffer, A., \& Kästner, M. (2011). Formation and fate of bound residues from microbial biomass during 2, 4-D degradation in soil. Environmental science \& technology, 45(3), 999-1006.

16. Ojo, J. (2016). Pesticides use and health in Nigeria. Ife Journal of Science, 18(4), 981-991. 
17. Perera, S. D., \& Dulmini, A. T. (2020). Chemical nature of pesticide. The Tri-Annual Publication of the Institute of Chemistry Ceylon. Vol. 37 No. 2. Pp 45-48.

18. Prüss-Ustün, A., Vickers, C., Haefliger, P., \& Bertollini, R. (2011). Knowns and unknowns on burden of disease due to chemicals: a systematic review. Environmental health, 10(1), 1-15.

19. Quijano, R. F. (2002) Endosulfan poisoning in Kasaragod, Kerala, India, Report on a fact finding mission.

20. Riedo, J., Wettstein, F. E., Rösch, A., Herzog, C., Banerjee, S., Büchi, L., ... \& van der Heijden, M. G. (2021). Widespread occurrence of pesticides in organically managed agricultural soils - the ghost of a conventional agricultural past?. Environmental Science \& Technology, 55(5), 2919-2928.

21. Roberts, J. R., Karr, C. J., Paulson, J. A., Brock-Utne, A. C., Brumberg, H. L., Campbell, C. C., ... \& Wright, R. O. (2012). Pesticide exposure in children. Pediatrics, 130(6), e1765-e1788.

22. Schumann, S. (2004). Environmental risk assessment of pesticides in Nepal and Hindukush-Himalayan region. In Comparative Risk Assessment and Environmental Decision Making (pp. 83-98). Springer, Dordrecht.

23. Sharma, A., Kumar, V., Shahzad, B., Tanveer, M., Sidhu, G. P. S., Handa, N., and Thukral, A. K. (2019). Worldwide pesticide usage and its impacts on ecosystem. SN Applied Sciences, 1(11), 1-16.

24. Silva, V., Mol, H. G., Zomer, P., Tienstra, M., Ritsema, C. J., \& Geissen, V. (2019). Pesticide residues in European agricultural soils-A hidden reality unfolded. Science of the Total Environment, 653, 1532-1545.

25. Singh, B.K, and Walker, A (2006) Microbial degradation of organophosphorus compounds. FEMS Microbiol Rev 30(3):428-471

26. Thurman, E. M., Ferrer, I., \& Zweigenbaum, J. A. (2008). Multiresidue analysis of 100 pesticides in food samples by LC. Triple Quadrupole Mass Spectrometry, Agilent technologies Publication

27. Tudi M, Daniel Ruan H, Wang L, Lyu J, Sadler R, Connell D, Chu C, Phung DT (2021). Agriculture Development, Pesticide Application and Its Impact on the Environment. International Journal of Environmental Research and Public Health. 2021; 18(3):1112. https://doi.org/10.3390/ijerph18031112

28. Ukalska-Jaruga, A., Smreczak, B., \& Siebielec, G. (2020). Assessment of pesticide residue content in Polish agricultural soils. Molecules, 25(3), 587.

29. U.S. Environmental Protection Agency: 2006 - 2007 Pesticide Market Estimate Usage. http://www. Epa.gov/opp ooo1/pesticides/07pestsales/usage2007.htm31. retrieved 01/11/21.

30. Weiss, B., Amler, S and Amler, R.W., (2004). Pesticides. Paediatrics 2004 113(4suppl):1030-1036.

31. Winard, H.K. 2016. Toxicity of Pesticides. https://extension.psu.edu/toxicity-of-pesticides. retrieved 13/12/2021. 12;56pm.

32. Wirsching, J., Pagel, H., Ditterich, F., Uksa, M., Werneburg, M., Zwiener, C., ... \& Poll, C. (2020). Biodegradation of Pesticides at the Limit: Kinetics and Microbial Substrate Use at Low Concentrations. Frontiers in microbiology, 11, 2107.

33. World Health Organization. (2008). The global burden of disease: 2004 update. World Health Organization.

34. Zhou Y, Liu W, Ye H (2006) Effects of pesticides metolachlor and S-metolachlor on soil microorganisms in aquisols. II. Soil respiration. J Appl Ecol 17(7):1305-1309 